\title{
Detection of KK-LC-1 Protein, a Cancer/Testis Antigen, in Patients with Breast Cancer
}

\author{
YASUSHI KONDO ${ }^{1,2}$, TAKASHI FUKUYAMA ${ }^{3}$, RUI YAMAMURA ${ }^{3}$, NOBUE FUTAWATARI ${ }^{4}$, \\ YOSHINOBU ICHIKI ${ }^{5}$, YOICHI TANAKA ${ }^{6}$, YATSUSHI NISHI ${ }^{2}$, YOSHIHITO TAKAHASHI $^{1,2}$, \\ HITOSHI YAMAZAKI ${ }^{7}$, NORITADA KOBAYASHI ${ }^{3}$ and MASAHIKO WATANABE ${ }^{1}$ \\ ${ }^{1}$ Department of Surgery, School of Medicine, Kitasato University, Sagamihara, Japan; \\ ${ }^{2}$ Division of Surgery, ${ }^{3}$ Division of Biomedical Research, and ${ }^{7}$ Division of Pathology, \\ Kitasato University Medical Center, Kitamoto, Japan; \\ ${ }^{4}$ Department of Surgery Ohashi Medical Center, Toho University, Tokyo, Japan; \\ ${ }^{5}$ Second Department of Surgery, University of Occupational and Environmental Health, Kitakyushu, Japan; \\ ${ }^{6}$ Department of Clinical Pharmacy, School of Pharmacy, Kitasato University, Tokyo, Japan
}

\begin{abstract}
Background: Kita-Kyushu lung cancer antigen-1 $(K K-L C-1)$ is a cancer/testis antigen and predominant target for cancer immunotherapy. Its detection is only established based on gene expression. In this study, we established a monoclonal antibody against $K K-L C-1$ to detect its protein expression in formalin-fixed samples. Materials and Methods: The monoclonal antibody against KK-LC-1 was evaluated and the detection of KK-LC-1 between gene expression and protein expression was compared in patients with breast cancer. The monoclonal antibody clone 34B3, which we established, stained testicular germ cells positively. Results: The rates of detection of KK-LC-1 gene and protein expression were $11.8 \%$ and $52.9 \%$, respectively. Protein expression was detected in all triple-negative breast cancer cases studied ( $n=8)$. Furthermore, KK-LC-1 was detected in all tumours without oestrogen receptor expression. Conclusion: This study indicated that KK-LC-1 expression was detected in breast cancer, especially in oestrogen receptor-negative subtypes.
\end{abstract}

Breast cancer is the most frequently diagnosed cancer in women. It is also a predominant cause of mortality (1). However, standard therapies for breast cancer have not reduced mortality. New therapies against breast cancer,

Correspondence to: Dr Takashi Fukuyama, Division of Biomedical Research, Kitasato University Medical Center, 6-100 Arai, Kitamoto, Saitama 364-8501, Japan. Tel: +81 485931236, Fax: +81 485931262, e-mail: fukuyam@insti.kitasato-u.ac.jp,

Key Words: KK-LC-1, cancer/testis antigen, breast cancer, monoclonal antibody. especially triple-negative breast cancer (TNBC), that cannot be applicable for hormone and HER2 therapy, are needed. A recent study indicated that inhibitors of immune checkpoints such as programmed death (PD)-1/PD ligand-1 interaction can restore the immune response of cytotoxic T-lymphocytes (CTLs) to tumour-associated antigens and have been successfully established as a new cancer therapy (2).

Several tumour-associated antigens have been identified in various human cancer types (3). These antigens are classified into four categories, excluding extrinsic viral antigens, as follows: cancer/testis antigens (CTAs), differentiation antigens, amplification or overexpression antigens, and tumour-specific mutated antigens recently defined as neo-antigens. CTAs are especially attractive targets for immunotherapy because they are not at all, or minimally expressed in normal tissues except for the testis, but are aberrantly expressed in a range of human cancer types (4). Therefore, immune targeting of these antigens is thought to have negligible adverse side-effects.

Kita-Kyushu lung cancer antigen-1 (KK-LC-1), also known as CT83 and CXORF61, is a CTA that has epitope peptides recognised by CTLs. When CTLs against KK-LC-1 accumulate predominantly among tumour-infiltrating lymphocytes, adaptive immunotherapy using such lymphocytes leads to a good response (5). $K K-L C-1$ maps to chromosome $\mathrm{Xq} 23$, and is not expressed in normal tissues except for the testis, but is expressed in $33 \%$ of non-small cell lung cancer $(6,7)$. Furthermore, KK-LC-1 was found to be expressed in $82 \%$ and $75 \%$ of patients with gastric cancer $(10)$ and $\operatorname{TNBC}(8,9)$.

Almost all studies about KK-LC-1 screening have evaluated its gene expression. Although some reports used polyclonal antibody (pAb) against KK-LC-1 $(9,10)$, we have also used it and determined that it was not able to distinguish 
Table I. Gene expression of studied cancer/testis antigen in 51 breast cancer cases.

\begin{tabular}{|c|c|c|c|c|}
\hline Gene symbol & Gene name & Positive & Negative & Frequency of positivity $(\%$ \\
\hline$M A G E-A 1$ & Melanoma antigen gene A1 & 21 & 30 & 41.2 \\
\hline$M A G E-A 3$ & Melanoma antigen gene $\mathrm{A} 3$ & 5 & 46 & 9.8 \\
\hline$M A G E-A 4$ & Melanoma antigen gene A4 & 3 & 48 & 5.9 \\
\hline$N Y-E S O-1$ & New York oesophageal squamous cell carcinoma-1 & 12 & 39 & 23.5 \\
\hline SSX4 & Synovial sarcoma, $\mathrm{X}$ breakpoint 4 & 7 & 44 & 13.7 \\
\hline$K K-L C-1$ & Kita-Kyushu lung cancer antigen- 1 & 6 & 45 & 11.8 \\
\hline
\end{tabular}

KK-LC-1 protein because there was no staining of testis, which strongly expresses KK-LC-1. We then established a new monoclonal antibody (mAb) to KK-LC-1. In this study, we evaluated the KK-LC-1 mAb (clone 34B3) which can be applied for immunohistochemistry (IHC) and investigated KK-LC-1 expression in breast cancer tumour using it.

\section{Materials and Methods}

The study protocol was approved by the Human Ethics Review Committee of the Kitasato University Medical Center, Japan (Approval No. 29-17), and all experiments were carried out in accordance with relevant guidelines and regulations. Signed informed consent was obtained from all patients prior to collection of the tissue samples used in this study.

Patients. A total of 154 patients underwent surgical resection for breast cancer at the Department of Surgery, Kitasato University Medical Center, Kitamoto, Japan, between June 2014 and August 2017. Before resection, signed informed consent we obtained from each patient. The fresh tumour mass was bisected and a tumour portion was picked from the centre of a bisected face. Whenever possible, a normal portion of the mammary gland distant from the tumour mass was sampled. Formalin-fixed paraffin-embedded (FFPE) sections were prepared from the periphery of the sampling area. The rate of tumour-inclusion of the fresh tumour samples was assessed through haematoxylin-eosin staining of the periphery. The samples used in this study included more than $10 \%$ of tumour cells. Finally, we obtained 51 sets of fresh and FFPE samples from tumour masses and, in four cases, a non-tumoural area including samples from the mammary gland, which was distant from the tumour mass, in the breast specimens after surgical resection. The clinicopathological findings were classified according to the General Rules for Clinical and Pathological Recording of Breast Cancer 2005 (11).

Tissue specimens. Fresh tumour and normal mammary gland samples were immediately stored at $4^{\circ} \mathrm{C}$ overnight in RNALater (Life Technologies, Carlsbad, CA, USA) and then stored at $-80^{\circ} \mathrm{C}$ until use. Each sample for assessment of gene expression was subjected to haematoxylin-eosin staining to confirm the predominance of tumour cells in the tumour area and to exclude contamination of tumour cells in the mammary gland which was distant from the tumour mass.
CTA expression. The total RNA from each sample was isolated using a QIACUBE and RNeasy Tissue Mini Kit (Qiagen, Hilden, Germany), according to the manufacturer's instructions. Total RNA was converted to cDNA using oligo $\mathrm{p}(\mathrm{dN}) 6$ random primers and Superscript III reverse transcriptase (Life Technologies). Expressions of $\beta$-actin $(A C T B)$; melanoma antigen (MAGE)-A1; MAGE-A3; MAGE-A4; synovial sarcoma, X break point 4 (SSX4); and New York oesophageal squamous cell carcinoma-1 (NY-ESO-1) were measured with TaqMan Gene Expression Assays (IDs: Hs99999903_m1, Hs00607097_m1, H200366532_m1, Hs00365979_m1, Hs00265824_m1, and Hs02341532_m1, respectively). Analyses were performed using a 7900HT Fast Real-Time PCR System (Life Technologies). The threshold cycle number of cDNAs converted from RNAs was measured for $A C T B$ then $<28$ threshold cycles were passed, and the samples were assessed for the expression of CTAs. Real-time polymerase chain reaction (PCR) was performed in a $20 \mu \mathrm{l}$ reaction containing $5 \mu \mathrm{l}$ of cDNA template, $10 \mu \mathrm{l}$ of FastStart Universal Probe Master Mix (Roche, Manheim, Germany), and $1 \mu \mathrm{l}$ of TaqMan Gene Expression Assay. $K K-L C-1$ expression was examined by 40 -cycle end-point RT-PCR because an appropriate probe to detect $K K-L C-1$ mRNA was unavailable at the time of this study. PCR amplification was performed in $20 \mu \mathrm{l}$ of PCR reactions containing $2 \mu \mathrm{l}$ of cDNA template, rTaq (Takara, Tsu, Japan), dNTPs (Roche, Basel, Switzerland), and $500 \mathrm{nM}$ each of gene-specific primers 5'ATGAACTTCTATTTACTCCTAGCGAGC-3' and 5'-TTAGGTGG ATTTCCGGTGAGG-3' (Sigma-Aldrich Japan, Shinagawa, Tokyo, Japan). The annealing temperature was $67^{\circ} \mathrm{C}$, and 40 cycles were used to yield the 342 -bp product. PCR products were visualised by ethidium bromide staining and ultraviolet light exposure after electrophoresis on $1.5 \%$ agarose gels. Detection of a visible band of 342-bp product was judged as positive expression.

Preparation of monoclonal antibody $(m A b)$ against $K K-L C-1$. The selection of antigenic peptide, peptide synthesis, and keyhole limpet hemocyanin conjugation was performed by Biogate (Gifu, Japan). Hydrophilicity, secondary structure, surface probability, and antigenicity were considered in the designation of the antigenic peptide sequence as follows. The hydrophilicity was evaluated by the method of Hopp and Woods (12). The secondary structure was evaluated by the method of Chou and Fasman (13) and the method of Robson (14) using GENETYX-MAC software (Software Development, Tokyo, Japan). The surface probability was evaluated by the method of Emini et al. (15). Antigenicity was evaluated by the method of Welling et al. (16) and the method of Parker et al. (17) using the original software. The designed peptide sequence was subjected to BLASTP search 
(http://www.ncbi.nlm.nih.gov/blast/) to screen its homology with known protein sequences. Based on these evaluations, residues 84 to 113 of KK-LC-1 were used as a candidate peptide. At the $N$-terminus of the synthesized peptide, a cysteine residue was added to facilitate conjugation to the carrier protein, keyhole limpet hemocyanin. The mouse monoclonal antibody against the peptide was prepared by CLEA Japan (Tokyo, Japan) using a standard protocol. The hybridomas producing the antibodies were screened by enzyme-linked immunosorbent assay with the synthesized peptide.

Immunohistochemical staining. FFPE sections $(3 \mu \mathrm{m})$ of human adult testis, breast tumour, and normal mammary gland distant from the tumour mass were prepared. Before the use of primary antibodies, antigen-retrieval for these sections was carried out by autoclaving at $121^{\circ} \mathrm{C}$ for $5 \mathrm{~min}$ in $10 \mathrm{mM}$ citrate buffer solution of $\mathrm{pH}$ 6.0. Endogenous peroxidase was blocked using $6 \% \mathrm{H}_{2} \mathrm{O}_{2}$. For KK-LC-1 staining, KK-LC-1 mAb 34B3 (1:80 dilution for $1 \mathrm{~h}$ ) and KK-LC-1 pAb (1:50 for 2 h; HPA003773; Sigma Life Science, St. Louis, MO, USA) were used as the primary antibodies. Enzymelabelled biotin-streptavidin techniques were applied throughout with the Histofine Histostainer 48A automated immunohistochemistry slide staining system (Nichirei Bioscience, Chuo, Tokyo, Japan). In breast cancer tumours, expression was assessed as the staining intensity of tumour cells.

Statistical analysis. Statistical analyses of KK-LC-1 expression according to each clinicopathological factor, gender, oestrogen receptor (ER), progesterone receptor (PgR), human epidermal growth factor receptor 2 (HER2), Ki67, nuclear grade, subtype and stage, was performed using Fisher's exact test. $p$-Values of less than 0.05 were considered significant. JMP8.0 (SAS institute Japan, Minato-ku, Japan) was used for the analysis.

\section{Results}

CTA gene expression of specimens in breast cancer tumours. In breast cancer tumours, six (11.8\%), 21 (41.2\%), five (9.8\%), three $(5.9 \%)$, seven $(13.7 \%)$, and $12(23.5 \%)$ out of 51 patients had positive expression of $K K-L C-1, M A G E-A 1, M A G E-A 3$, $M A G E-A 4, S S X 4$, and NY-ESO-1, respectively (Table I).

Evaluation of $K K-L C-1 \quad m A b 34 B 3$. IHC was performed using KK-LC-1 mAb 34B3, and commercial pAb with the FFPE sections of testis. The mAb strongly stained germline cells in seminiferous tubule (Figure 1A). On the contrary, despite following the manufacturer's protocol, the pAb did not stain germline cells (Figure 1B). We then evaluated the expression level of KK-LC-1 in breast cancer tumour using $\mathrm{mAb}$. There was no staining of normal mammary gland, distant from tumour, in the four paired samples (Figure 1C). Representative negative (Figure 1D), weak (Figure 1E and F) and strong (Figure 1G) staining of breast tumours is depicted in Figure 1D-G, respectively.

Detection of KK-LC-1 gene and protein expression. The rate of KK-LC-1 detection was $11.8 \%$ and $52.9 \%$ as assessed by gene and protein expression, respectively (Table II). For all
A

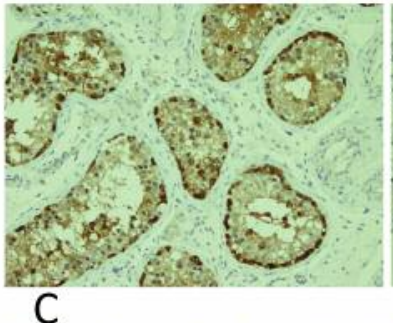

B
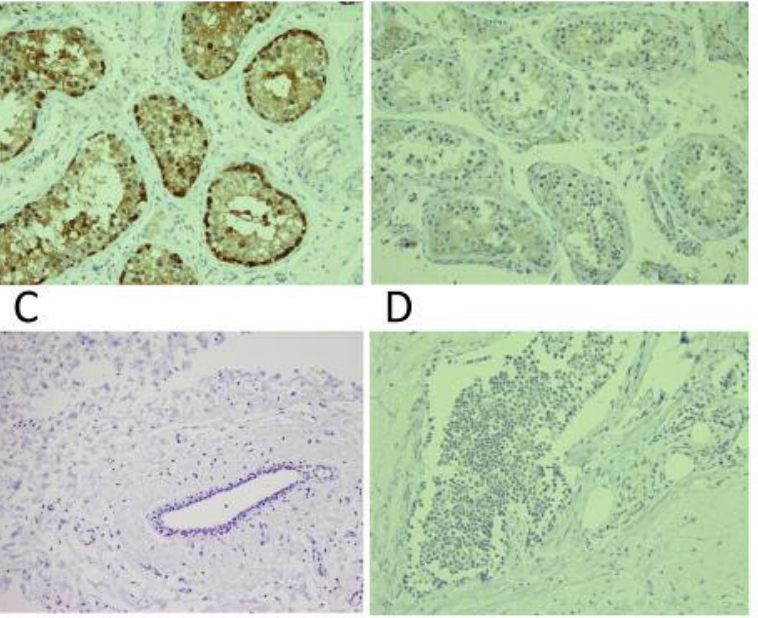

D

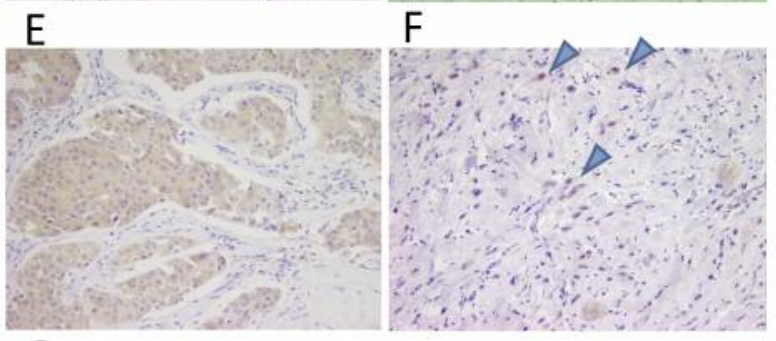

G

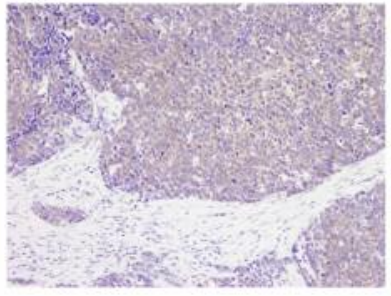

Figure 1. Representative staining against Kita-Kyushu lung cancer antigen-1 (KK-LC-1). Clone $34 B 3$ monoclonal antibody to KK-LC-1 (A) and a polyclonal antibody $(B)$ were used in immunohistochemical staining of testis. Germ cells on the basal membrane were strongly stained and judged as $++(A)$, although polyclonal antibody did not stain tissue and was judged as negative $(B)$. Staining patterns of monoclonal antibody clone $34 B 3$ against KK-LC-1 was evaluated using breast specimens. C: Normal mammary gland tissue distant from the tumour mass was not stained. D: A specimen with negative staining (-). E and $F$ : Specimens with weakly positive staining (+). Arrowheads indicate the stained tumor cells in F. G: A specimen with strongly positive staining $(++)$. Original magnification, $\times 200$.

specimens in which $K K-L C$ - 1 gene expression was detected its protein expression was also detected (Figure 2). KK-LC1 protein expression was detected in $100 \%$ of ER-negative cases. Detection considering both gene and protein expression also showed that KK-LC-1 was more frequently expressed in the ER-negative group than in the ER-positive group, in the PgR-negative group than PgR-positive group 
Table II. Kita-Kyushu lung cancer antigen-1 (KK-LC-1) gene and protein expression according to clinicopathological factors.

\begin{tabular}{|c|c|c|c|c|c|}
\hline & Case & Gene expression, $\mathrm{n}(\%)$ & $p$-Value & Protein expression, $\mathrm{n}(\%)$ & $p$-Value \\
\hline Total & 51 & $6(11.8)$ & & $28(54.9)$ & \\
\hline \multicolumn{6}{|l|}{ Gender } \\
\hline Male & 2 & $0(0.0)$ & \multirow[t]{2}{*}{$>0.99$} & $1(50.0)$ & \multirow[t]{2}{*}{$>0.99$} \\
\hline Female & 49 & $6(12.2)$ & & $27(55.1)$ & \\
\hline \multicolumn{6}{|c|}{ Oestrogen receptor } \\
\hline Positive & 41 & $1(2.4)$ & \multirow[t]{2}{*}{0.0005} & $18(43.9)$ & \multirow[t]{2}{*}{0.0011} \\
\hline Negative & 10 & $5(50.0)$ & & $10(100.0)$ & \\
\hline \multicolumn{6}{|c|}{ Progesterone receptor } \\
\hline Positive & 39 & $1(2.6)$ & \multirow[t]{2}{*}{0.0018} & $18(46.2)$ & \multirow[t]{2}{*}{0.0441} \\
\hline Negative & 12 & $5(41.7)$ & & $10(83.3)$ & \\
\hline \multicolumn{6}{|l|}{ HER2 } \\
\hline Positive & 8 & $2(25.0)$ & \multirow[t]{2}{*}{0.2339} & $6(75.0)$ & \multirow[t]{2}{*}{0.2485} \\
\hline Negative & 43 & $4(9.3)$ & & $22(51.2)$ & \\
\hline \multicolumn{6}{|l|}{ Ki67 } \\
\hline$>50 \%$ & 11 & $4(36.4)$ & \multirow[t]{4}{*}{0.0166} & $8(72.7)$ & \multirow[t]{4}{*}{0.3062} \\
\hline $20-50 \%$ & 12 & $1(8.3)$ & & $8(66.7)$ & \\
\hline$<20 \%$ & 27 & $1(3.7)$ & & $12(44.4)$ & \\
\hline ND & 1 & 0 & & 0 & \\
\hline \multicolumn{6}{|l|}{ Nuclear grade } \\
\hline 1 & 27 & $2(7.4)$ & \multirow[t]{4}{*}{0.0179} & $11(40.7)$ & \multirow[t]{4}{*}{0.1805} \\
\hline 2 & 11 & $0(0.0)$ & & 7 (63.6) & \\
\hline 3 & 11 & $4(36.4)$ & & $8(72.7)$ & \\
\hline ND & 2 & 0 & & 2 & \\
\hline \multicolumn{6}{|l|}{ Subtype } \\
\hline Luminal A & 32 & $0(0.0)$ & \multirow[t]{4}{*}{0.0036} & $14(43.8)$ & \multirow[t]{4}{*}{0.0046} \\
\hline Luminal B & 9 & $1(11.1)$ & & $4(44.4)$ & \\
\hline HER2 & 2 & $1(50.0)$ & & $2(100.0)$ & \\
\hline TNBC & 8 & $4(50.0)$ & & $8(100.0)$ & \\
\hline \multicolumn{6}{|l|}{ Stage } \\
\hline 0 & 2 & $0(0.0)$ & \multirow[t]{5}{*}{$>0.99$} & $0(0.0)$ & \multirow[t]{5}{*}{0.2445} \\
\hline I & 17 & $2(11.8)$ & & $8(47.1)$ & \\
\hline II & 21 & $4(19.0)$ & & $16(76.2)$ & \\
\hline III & 9 & $0(0.0)$ & & $3(33.3)$ & \\
\hline IV & 2 & $0(0.0)$ & & $1(50.0)$ & \\
\hline
\end{tabular}

HER2, Human epithelial growth factor receptor 2, ND: not determined, TNBC: triple-negative breast cancer.

and TNBC than all other subtypes. Detection of gene expression showed that $K K-L C-1$ was most frequently expressed in the group with a Ki67 index of more than $50 \%$, and with nuclear grade 3 .

\section{Discussion}

Evaluation of gene expression should be performed with fresh specimens when the quantity of target gene expression is low. CTAs evaluated in this study were weakly expressed in the tumours, and we ventured to prepare fresh breast cancer tumours. Furthermore, we made FFPE sections from around the sampling area for evaluating gene expression because the sampling area itself reflects the dominance of tumour cells compared with stromal cells. Although we sampled the centre of the tumour mass, nine out of 60 samples (15\%) were not used in this study because of a tumour-inclusion rate of less than $10 \%$.

CTAs are expressed in melanomas and lung, oesophageal, gastric, colon, and breast carcinomas, but not in normal tissues except for germline tissues. They are attractive targets for cancer therapy and diagnosis. In our study, the gene expression of CTAs was close to those in previous reports by other laboratories except for $M A G E-A l$ (18-22). Our gene expression data for $M A G E-A l$ were similar to reported protein expression data (23).

In our study, KK-LC-1 was detected by mAb in all specimens in which its gene expression was detected. These data indicate the accuracy of this mAb. Furthermore, the detection rate with $\mathrm{mAb}$ was higher than detection of gene expression. One of the causes of their difference might be that the $\mathrm{mAb}$ might detect a minor population of tumour 


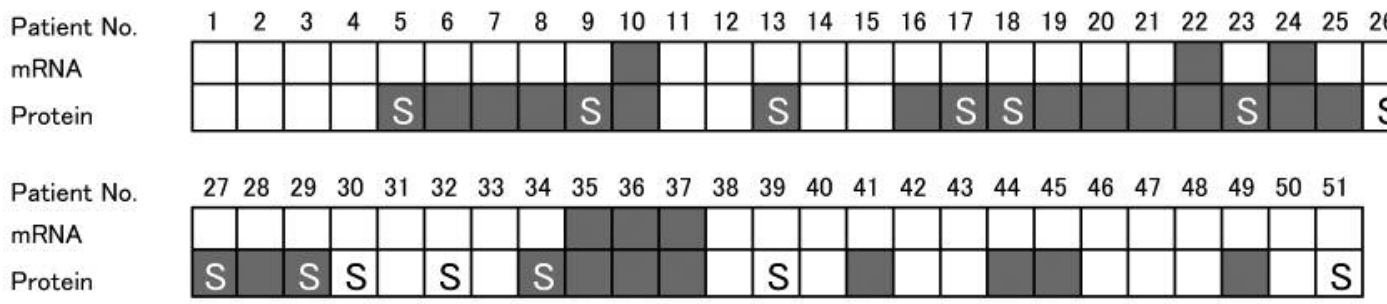

Figure 2. Detection of Kita-Kyushu lung cancer antigen-1 (KK-LC-1) gene and protein expression. Breast cancer tumour specimens were assessed for the gene expression of KK-LC-1 using reverse transcription-polymerase chain reaction ( $m R N A$ row) and protein expression using immunohistochemistry (protein row). Open squares indicate no expression and closed squares indicate expression of KK-LC-1. S, Stromal cells occupied 50-90\% of the sampling area, as stained by haematoxylin and eosin.

cells, such as diffuse type. Similarly, for breast carcinoma, detection of MAGE-A1 with mAb was higher at $69 \%$ than that of gene expression reported by Yao et al. (11.8\%) and that of the present study $(41.2 \%)$. In addition, detection of NY-ESO-1 with mAb was higher at $27 \%$ than that of gene expression reported by Yao et al. $(4.4 \%)(22,23)$.

Our results showed that KK-LC-1 was expressed in the tumour of ER-negative subtype, including TNBC. ER-negative tumours are more likely to confer a poor prognosis; a higher recurrence rate was reported for ER-negative breast cancer (24). Therapy with oestrogen antagonist is not applicable for patients with ER-negative tumour so that alternative therapies for ER-negative tumours are desired. Recently, KK-LC-1 peptides restricted by HLA-A1,-A2, and-B62 were discovered $(5,7,9)$. The frequencies of expression of these HLAs among Japanese were reported to be $1 \%, 45 \%$, and $15 \%$, respectively. On the contrary, those among Caucasians were reported to be $28 \%, 49 \%$, and $12 \%$, respectively $(25,26)$. Considering that KK-LC-1 was found to be expressed in all patients with ERnegative breast cancer and the frequency of patients expressing at least one of these HLA proteins was estimated at 55\% among Japanese and $67 \%$ among Caucasians, immunotherapies targeting KK-LC-1 for ER-negative breast cancer, including TNBC, might represent a new treatment strategy.

The mAb constituted by us specifically bound KK-LC-1, which was specifically expressed in testicular germline cells and tumour cells. Our results using this $\mathrm{mAb}$ indicate that KK-LC-1 was expressed in all ER-negative breast cancer tumours and might be an attractive target for cancer immunotherapy.

\section{Acknowledgements}

T. Fukuyama acknowledges support from JSPS KAKENHI (17K16578), Takeda Science Foundation, a Kitasato University Research Grant for Young Researchers, and Grant-in-Aid for research from Kitasato University Medical Center (H27-002). The Authors thank Nihon CLEA Co. Ltd. for support in establishing mAb, Ms. Mariko Ogi and Mr. Hisao Sekine for their technical assistance, and Enago (www.enago.jp) for English language review.

\section{References}

1 Torre LA, Islami F, Siegel RL, Ward EM and Jemal A: Global Cancer in Women: Burden and Trends. Cancer Epidemiol Biomark Prev 26: 444-457, 2017.

2 Topalian SL, Hodi FS, Brahmer JR, Gettinger SN, Smith DC, McDermott DF, Powderly JD, Carvajal RD, Sosman JA, Atkins MB, Leming PD, Spigel DR, Antonia SJ, Horn L, Drake CG, Pardoll DM, Chen L, Sharfman WH anders RA, Taube JM, McMiller TL, Xu H, Korman AJ, Jure-Kunkel M, Agrawal S, McDonald D, Kollia GD, Gupta A, Wigginton JM and Sznol M: Safety, activity and immune correlates of anti-PD-1 antibody in cancer. N Engl J Med 366: 2443-2454, 2012.

3 van der Bruggen $\mathrm{P}$, Traversari C, Chomez $\mathrm{P}$, Lurquin $\mathrm{C}$, De Plaen E, Van den Eynde B, Knuth A and Boon T: A gene encoding an antigen recognized by cytolytic T-lymphocytes on a human melanoma. Science 254: 1643-1647, 1991.

4 Scanlan MJ, Simpson AJ and Old LJ: The cancer/testis genes: review, standardization and commentary. Cancer immunity 4: 1, 2004.

5 Stevanovic S, Pasetto A, Helman SR, Gartner JJ, Prickett TD, Howie B, Robins HS, Robbins PF, Klebanoff CA, Rosenberg SA and Hinrichs CS: Landscape of immunogenic tumor antigens in successful immunotherapy of virally induced epithelial cancer. Science 356: 200-205, 2017.

6 Shigematsu Y, Hanagiri T, Shiota H, Kuroda K, Baba T, Mizukami M, So T, Ichiki Y, Yasuda M, So T, Takenoyama M and Yasumoto K: Clinical significance of cancer/testis antigens expression in patients with non-small cell lung cancer. Lung Cancer 68: 105-110, 2010.

7 Fukuyama T, Hanagiri T, Takenoyama M, Ichiki Y, Mizukami M, So T, Sugaya M, So T, Sugio $K$ and Yasumoto $K$ : Identification of a new cancer/germline gene, KK-LC-1, encoding an antigen recognized by autologous CTL induced on human lung adenocarcinoma. Cancer Res 66: 4922-4928, 2006.

8 Shida A, Futawatari N, Fukuyama T, Ichiki Y, Takahashi Y, Nishi Y, Kobayashi N, Yamazaki H and Watanabe M: Frequent high expression of Kita-Kyushu lung cancer antigen-1 (KK-LC-1) in Gastric Cancer. Anticancer Res 35: 3575-3579, 2015.

9 Paret C, Simon P, Vormbrock K, Bender C, Kolsch A, Breitkreuz A, Yildiz O, Omokoko T, Hubich-Rau S, Hartmann C, Hacker S, Wagner M, Roldan DB, Selmi A, Tureci O and Sahin U: CXORF61 is a target for T-cell-based immunotherapy of triplenegative breast cancer. Oncotarget 6: 25356-25367, 2015. 
10 Cohen AS, Khalil FK, Welsh EA, Schabath MB, Enkemann SA, Davis A, Zhou JM, Boulware DC, Kim J, Haura EB and Morse DL: Cell-surface marker discovery for lung cancer. Oncotarget 8: 113373-113402, 2017.

11 Sakamoto G, Inaji H, Akiyama F, Haga S, Hiraoka M, Inai K, Iwase T, Kobayashi S, Sakamoto G, Sano M, Sato T, Sonoo H, Tsuchiya $\mathrm{S}$ and Watanabe $\mathrm{T}$ : General rules for clinical and pathological recording of breast cancer 2005. Breast Cancer 12(Suppl): S1-27, 2005.

12 Hopp TP and Woods KR: Prediction of protein antigenic determinants from amino acid sequences. Proc Natl Acad Sci USA 78: 3824-3828, 1981.

13 Chou PY and Fasman GD: Prediction of protein conformation. Biochemistry 13: 222-245, 1974.

14 Garnier J, Osguthorpe DJ and Robson B: Analysis of the accuracy and implications of simple methods for predicting the secondary structure of globular proteins. J Mol Biol 120: 97-120, 1978.

15 Emini EA, Hughes JV, Perlow DS and Boger J: Induction of hepatitis A virus-neutralizing antibody by a virus-specific synthetic peptide. J Virol 55: 836-839, 1985.

16 Welling GW, Weijer WJ, van der Zee R and Welling-Wester S: Prediction of sequential antigenic regions in proteins. FEBS Lett 188: 215-218, 1985.

17 Parker JM, Guo D and Hodges RS: New hydrophilicity scale derived from high-performance liquid chromatography peptide retention data: correlation of predicted surface residues with antigenicity and X-ray-derived accessible sites. Biochemistry 25 : 5425-5432, 1986

18 Ugur S, Özlem T, Yao-Tseng C, Gerhard S, Carlos V-H, J. OL and Michael P: Expression of multiple cancer/testis (CT) antigens in breast cancer and melanoma: Basis for polyvalent $\mathrm{CT}$ vaccine strategies. Int J Cancer 78: 387-389, 1998.

19 Mashino K, Sadanaga N, Tanaka F, Yamaguchi H, Nagashima $\mathrm{H}$, Inoue $\mathrm{H}$, Sugimachi $\mathrm{K}$ and Mori M: Expression of multiple cancer-testis antigen genes in gastrointestinal and breast carcinomas. Br J Cancer 85: 713-720, 2001.
20 Tureci O, Chen YT, Sahin U, Gure AO, Zwick C, Villena C, Tsang S, Seitz G, Old LJ and Pfreundschuh M: Expression of SSX genes in human tumors. Int J Cancer 77: 19-23, 1998.

21 J. SM, O. GA, A. JA, J. OL and Yao-Tseng C: Cancer/testis antigens: an expanding family of targets for cancer immunotherapy. Immunol Rev 188: 22-32, 2002.

22 Yao J, Caballero OL, Yung WK, Weinstein JN, Riggins GJ, Strausberg RL and Zhao Q: Tumor subtype-specific cancer-testis antigens as potential biomarkers and immunotherapeutic targets for cancers. Cancer Immunol Res 2: 371-379, 2014.

23 Mrklić I, Spagnoli GC, Juretić A, Pogorelić Z and Tomić S: Coexpression of cancer testis antigens and topoisomerase 2-alpha in triple-negative breast carcinomas. Acta Histochemica 116: 740-746, 2014.

24 Kinne DW, Butler JA, Kimmel M, Flehinger BJ, MenendezBotet $\mathrm{C}$ and Schwartz M: Estrogen receptor protein of breast cancer in patients with positive nodes. High recurrence rates in the postmenopausal estrogen receptor-negative group. Arch Surg 122: 1303-1306, 1987.

25 Ikeda N, Kojima H, Nishikawa M, Hayashi K, Futagami T, Tsujino T, Kusunoki Y, Fujii N, Suegami S, Miyazaki Y, Middleton D, Tanaka H and Saji H: Determination of HLA-A,-C,-B,-DRB1 allele and haplotype frequency in Japanese population based on family study. Tissue Antigens 85: 252-259, 2015.

26 Mori M, Beatty PG, Graves M, Boucher KM and Milford EL: HLA gene and haplotype frequencies in the North American population: The National Marrow Donor Program Donor Registry. Transplantation 64: 1017-1027, 1997.

Received August 28, 2018

Revised September 9, 2018

Accepted September 13, 2018 